\title{
A model for amphipod (Talitrus saltator) population dynamics
}

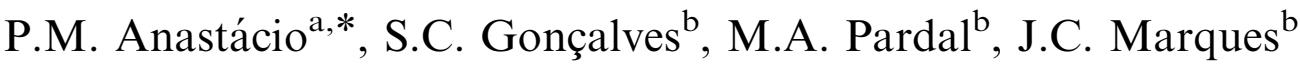

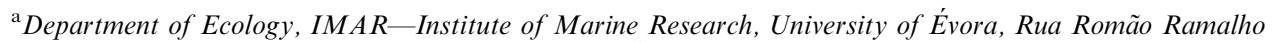 \\ 59, 7000-671 Évora, Portugal \\ ${ }^{\mathrm{b}}$ Department of Zoology, IMAR_Institute of Marine Research, Faculty of Sciences and Technology, \\ University of Coimbra, 3004-517 Coimbra, Portugal
}

Received 23 October 2001; accepted 31 July 2002

\begin{abstract}
This study provides a population dynamics model for one of the most common species (Talitrus saltator) in sandy beaches. Sensitivity analysis showed that in the model the abundance of $T$. saltator is deeply affected by variations in the minimum recruitment day length, the minimum temperature at recruitment, and the period between recruitments. The mortality rate, as expected, also had a profound effect on model performance. The abundance (IST, ind $\mathrm{m}^{-1}$ ) of T. saltator was most sensitive to the initial number of individuals in age class 5 (ca. 4 months old) and least sensitive to the initial number in age class 9 (ca. 8 months old). Data used for the calibration of the model were obtained in the Lavos beach in central Portugal. The model is based on differential equations and it was constructed using Stella simulation software. Five different model versions were tested corresponding to different modes of recruitment that could fit the data. It was found that the best model was obtained when considering reproduction dependent on temperature and photoperiod and occurring on a semi-lunar basis. Two out of the five different model versions tested gave a good statistical performance. Only one of these two model versions makes an effective use of causality mechanisms. This was also the model with the best intercept and slope of the simulated vs. observed regression equation. The other statistically satisfactory model used continuous reproduction between two dates. These dates do not match a photoperiod threshold. The final model version (e) may serve as a useful tool, when used alone or when coupled with other models. One of its uses could be in assessing the effects of human actions upon a sandy beach ecosystem.
\end{abstract}

(C) 2003 Elsevier Ltd. All rights reserved.

Keywords: sandy beaches; sandhopper; Crustacea; recruitment; photoperiod; temperature; Atlantic Ocean; Portugal

\section{Introduction}

Talitrid amphipods constitute one of the predominant arthropod groups in sandy beach fauna (Dahl, 1945, 1952; Lagardere, 1966; Pallualt, 1954; Weslawski, Stanek, Siewert, \& Beer, 2000), exhibiting a dynamic equilibrium with the environment. Due to their ecological importance, talitrids have been studied worldwide. Talitrids include key species such as the sandhopper Talitrus saltator, which is widely distributed and generally abundant where it occurs. The oscillations of T. saltator population size, its reproductive strategies, its efficiency in using available energy and its productivity,

\footnotetext{
* Corresponding author.

E-mail address: anast@uevora.pt (P.M. Anastácio).
}

are important for understanding not only the bioecology of the animal, but also to its ecology and role in the sandy beach ecosystem.

In the literature, several studies address Talitrus saltator reproductive biology (David, 1936; Williams, 1978, 1979, 1985; Williamson, 1951) and population dynamics (Lagardere, 1966; Scapini, Chelazzi, Colombini, \& Fallaci, 1992; Weslawski, Kupidura, \& Zabicki, 2000; Williams, 1978, 1995). These studies are fundamental but with few exceptions (e.g. Williams, 1985) the causality of the processes affecting population dynamics is not thoroughly studied. This becomes even more relevant considering that behavioural and physiological adaptations may differ throughout the distribution range of $T$. saltator. This has been observed in other species (Kevin \& Spicer, 1998; Morrit \& Spicer, 1998) and recent data from Marques et al. (2003) clearly show 
geographical differences in population biology of T. saltator. Moreover, a large number of papers have been published on several aspects of talitrids behaviour and some of them linked behaviour with ecological conditions (e.g. Fallaci et al., 1999; Morrit, 1998; Nardi, Persson, \& Scapini, 2000; Scapini, 1997; Williams, 1983).

All this data permit the construction of a model. Ecological models lead to a higher degree of awareness of the gaps in our knowledge. Moreover, by building a population dynamics model of Talitrus saltator a tool for future predictions under various scenarios is built. This can be used in order to understand or mitigate the impacts that environmental changes (e.g. human impact) may have over one of the most common supralittoral species of sandy beaches.

It is the purpose of the present study that the model will accomplish the following goals: (a) a correct simulation of the population dynamics of Talitrus saltator; (b) consideration of the most important ecological processes involved in the population dynamics of the species; and (c) provide indications for further research, namely on the relative importance of each parameter or process on the dynamics of the population.

\section{Materials and methods}

\subsection{Study site}

Lavos sandy beach in the central region of Portugal is approximately $25 \mathrm{~km}$ long, between the mouth of the Mondego River and the Ervedeira coastal lagoon, close to Pedrógão, a small village. It is a relatively undisturbed beach, which receives a moderate number of summer visitors. The site chosen for the study, Cabedelo $\left(40^{\circ} 07^{\prime} 32^{\prime \prime} \mathrm{N} 8^{\circ} 51^{\prime} 49^{\prime \prime} \mathrm{W}\right)$, was located at about $1 \mathrm{~km}$ south from the Mondego River mouth, constituting a very exposed beach. The eulittoral zone was about $60 \mathrm{~m}$ in width, with an average slope of $2 \%$. Tidal range varies between 2 and $3.5 \mathrm{~m}$, and consequently the intertidal area ranges from approximately $30 \mathrm{~m}$, on neap tides, to $45 \mathrm{~m}$ in width, on spring tides. During storms, the beach may be almost completely inundated, which causes the deposition of large masses of drift wrack, mainly composed of macroalgae from rocky shores located to the north. The sediment is classified as medium sand, with a mean grain size between 0.250 and $0.500 \mathrm{~mm}$, based on samples taken with a 3 months periodicity according to the Wentworth scale (Brown \& McLachlan, 1990). No vegetation is found in the supralittoral area. The foredune is approximately $2.5-$ $3 \mathrm{~m}$ in height, with vegetation cover dominated by a single species, Ammophila arenaria. In the secondary dune Euphorbia paralias and Cakile maritima are the most important species.

\subsection{Data background}

The calibration and replicative validation of the model were performed using data from Talitrus saltator population structure on the coast of Lavos. These data were collected fortnightly by Marques et al. (2003) during 1999 using two strip transects with replication at each beach level. Data used in the model included, life span, individuals per strip transect (IST, ind $\mathrm{m}^{-1}$ ) (Brazeiro \& Defeo, 1996; McLachlan et al., 1981) recruitment periods, growth, sex ratio and age of sexual maturation. Mortality rates were also calculated from the data of Marques et al. (2003) by fitting exponential decay equations to the abundance (IST, ind $\mathrm{m}^{-1}$ ) of each cohort during the period when it was identified. This procedure assumes a constant value for the mortality of each cohort throughout its entire life. No consistent length or weight dependent daily mortality rates were found. An average of the mortalities calculated for each cohort was determined with a value of $0.00993 \mathrm{day}^{-1}$ (s.d. of 0.00757 ) and a median value of $0.00638 \mathrm{day}^{-1}$ was found for the cohorts identified. These values were then converted into proportions dead during the time spent in an age class (e.g. 28 days) in order to satisfy the needs of the model. Other important information, such as fecundity, was obtained from previously published papers (e.g. Williams, 1978) and then checked for model performance. In the case of the fertility some of the versions of the model used a weight vs. fertility regression but the final one relied on an average value of 13 young per female.

\subsection{Model structure}

The basic unit of the model is an age class. Each sandhopper entering an age class takes 45 or 28 days to reach the next one depending on the model version. At the end of the final age class sandhoppers reach the maximum possible life duration. Weight and recruitment are calculated in two separate modules.

In the study area recruitment takes place from early March to late September (Marques et al., 2003). Three different peaks of Talitrus saltator abundance (IST, ind $\mathrm{m}^{-1}$ ) were observed. Nevertheless only two peaks of juvenile abundance were detected (Marques et al., 2003). Different model versions were built in an attempt to match the observed abundance values. These versions used several continuous or discontinuous recruitment patterns and processes always based on the field data and the available literature.

The first approach tested four different types or timings for recruitment (model versions (a)-(d)) that could explain the observed data. Average sandhopper weight was calculated for each of eight age-class time intervals as described by Anastácio, Nielsen, and Marques (1999) (see section 2.4). The increase in weight 
for each 45-day period was regulated by the temperature. At very low winter temperatures (Bregazzi \& Naylor, 1972; Dahl, 1952; David, 1936; Palluault, 1954; Williams, 1995) and at extremely high summer temperatures (Scapini et al., 1992), sandhoppers retreat to burrows and therefore it was assumed that growth was arrested. Fertility was considered dependent on the weight (Williams, 1978) and several mechanisms to start recruitment were tested (see section 2.4).

The second approach (model version (e)) is considerably simpler than the previous one. Eleven, instead of eight, age classes, were used lasting 28 days each. This value was chosen taking into account the need to test smaller intervals in the age classes and also the lunar influence in the synchronization of moult and reproduction in the population (Williams, 1979). No parallel structure was used in order to simulate the weight of the animals and therefore fertility was considered as a constant value per female, independent of its age. In fact although Williams (1978) showed a clear increase in fertility with size this was not explored due to egg loss during handling. This approach uses a minimum and a maximum temperature and a minimum day length to proceed with the recruitment. This is in accordance with findings by Marques et al. (2003). Recruitment takes place with a semi-lunar periodicity (Williams, 1979) and it was considered that the contributions for recruitment start only near the end of age class 4 (Marques et al., 2003). This was accomplished by considering age classes $1-3$ as totally constituted by juveniles (or immature) and age class 4 as having only a small percentage of adults capable of reproduction.

\subsection{Equations for the model versions $(a)-(d)$}

Sandhopper growth in weight may be predicted by Eq. (1) (Table 1). The widely used von Bertalanffy equation for the growth in length is a modified and nondifferential approach to Bertallanfy (1957) equation for the instantaneous growth in weight (Eq. (1)). The length values obtained by Marques et al. (2003) using a von Bertalanffy equation were transformed to dry weights by a size/weight equation calculated for the study area (Gonçalves, personal communication). These weights were then used in order to calculate parameters $h$ and $k$ for Eq. (1).

Eq. (2) calculates the weight of an individual leaving an age class. This is based on: (1) its weight when it was leaving the previous age class (i.e. 45 days ago); (2) the estimated daily increase in weight; (3) a temperature regulation of the speed of growth; and (4) the number of days in which growth was possible.

Eq. (3) presents the temperature regulator for growth, $f_{(T)}$ obtained from Bowie et al. (1985), which has the shape of a skewed normal distribution. In order to parameterise this function the following values were used according to unpublished results from Colombini and Chellazi: maximum temperature $28.8^{\circ} \mathrm{C}$, minimum temperature $9{ }^{\circ} \mathrm{C}$, and optimum temperature $24.7^{\circ} \mathrm{C}$. This is in accordance with data showing that the species was active from 10 to $28.8^{\circ} \mathrm{C}$ (Scapini et al., 1992).

Analysis of field data did not demonstrate any age, size or weight dependent mortality rates and for this reason a common value was used for all the age classes. The value used in the model is the proportion dead during the period of an age class, i.e. 45 or 28 days depending on the model version.

Fertility depends on the size of Talitrus saltator (Williams, 1978) and therefore Eq. (4) was used. Data obtained in the study area indicate that recruitment occurs from early March to late September (Marques et al., 2003). Three different peaks of $T$. saltator abundance (IST, ind $\mathrm{m}^{-1}$ ) were observed. Nevertheless only two peaks of juvenile abundance were detected (Marques et al., 2003). Different model versions were built in an attempt to match the observed abundance values. Therefore four types of recruitment were tested:

Version (a) - a single and long reproduction period only dependent on the day of the year. A photoperiod-based regulation of reproduction such as the one demonstrated by Williams (1985) would fit this type. Nevertheless different photoperiod thresholds would apply.

Version (b) - two reproduction periods only dependent on the day of the year.

Version (c) - three reproduction periods only dependent on the day of the year.

Version (d) - reproduction dependent on the temperature and day length as suggested in the conclusions by Marques et al. (2003).

No causality in the recruitment process was used in model versions (a)-(c). Each of these model versions involved a different set of equations, therefore the comparison of the results of each version will act (sensu lato) as a form of sensitivity analysis for the equations.

Version (a) used Eq. (5) for the regulation of recruitment. This equation is similar to the one presented for the regulation of growth by the temperature. It provides an adequate shape of the recruitment curve but it needs to be multiplied by two other values in order to obtain the number of new recruits each day. These values are: (1) the number of new recruits that would be released if all the mature females were giving birth, and (2) the maximum percentage of mature females releasing new recruits.

For the simulation of each wave of recruitment versions (b) and (c) used Eq. (7), which is simply a modification of the equation for a normal distribution (Sokal \& Rohlf, 1987). Eq. (7) multiplied by the number of new recruits that would be released if all the 
Table 1

Equations used in the model

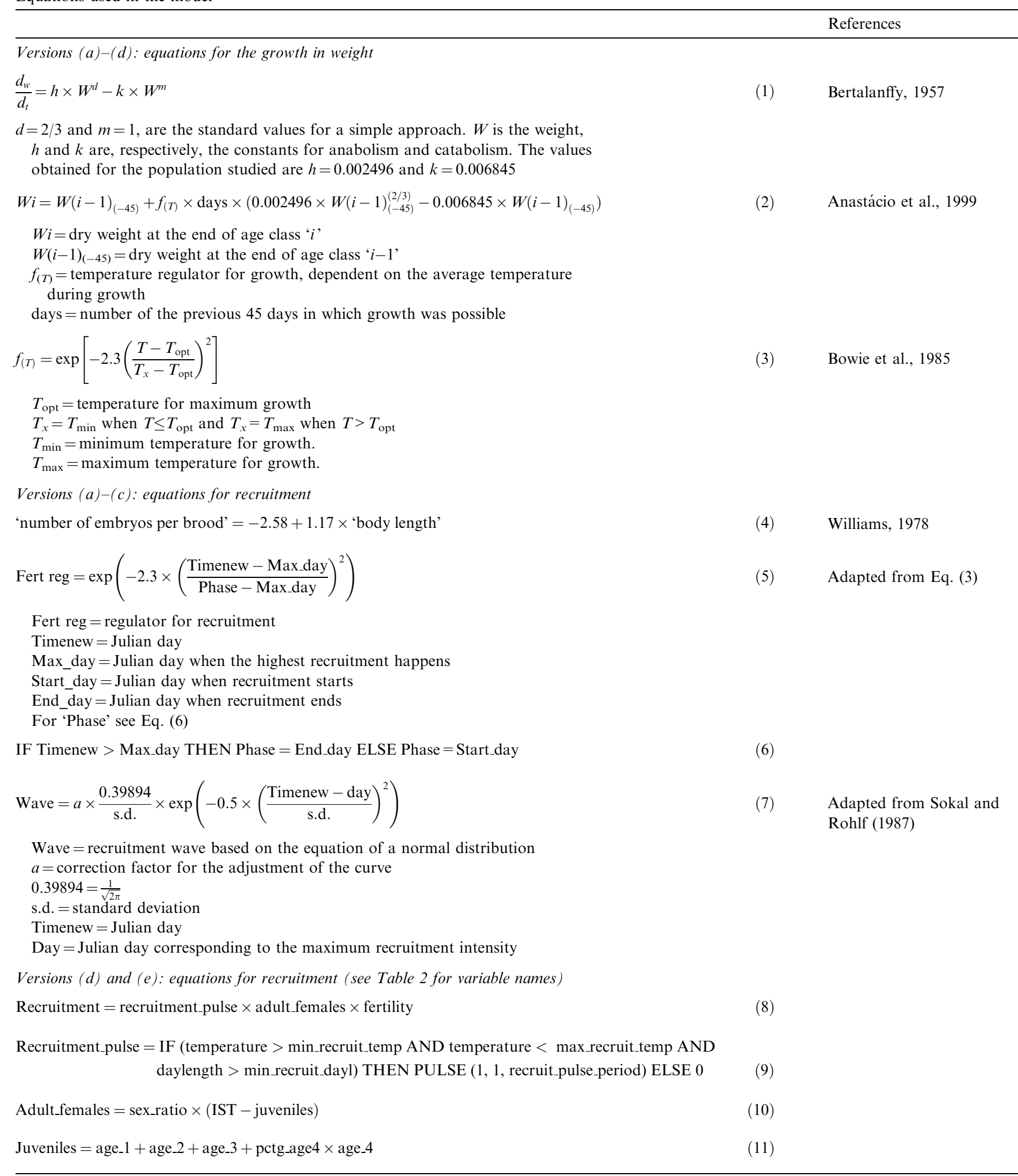

mature females were giving birth will provide the value for the new recruits at each day. The parameter values for this equation are different for each model version and for each recruitment wave. For model version (b), first recruitment wave: $a=1.9$, day $=140$, and s.d. $=$ 20; second recruitment wave: $a=0.15$, day $=223$, and s.d. $=21.0236$. For model version (c), first recruitment wave: $a=0.8$, day $=110$, and s.d. $=6$; second 
recruitment wave: $a=1.3$, day $=160$, and s.d. $=4$. Third recruitment wave: $a=0.3$, day $=235$, and s.d. $=6$.

Model version (d) used Eqs. (8)-(11) to simulate recruitment. In this version recruitment takes place if the temperature and day length fall within the right values. Recruitment will also happen on a periodical basis (e.g. based on a lunar cycle). The model used a value of $14^{\circ} \mathrm{C}$ for the minimum temperature for recruitment, $27^{\circ} \mathrm{C}$ for the maximum temperature for recruitment, and $13 \mathrm{~h}$ for the minimum day length (see Table 2).

\subsection{Equations for the model version (e)}

This is a simpler approach in which a smaller number of equations are needed (Table 1). Equations defined in the previous approach for growth (and its temperature regulation), and female fertility do not apply in the present case. Instead of calculating the fertility of the females from each age class a value of 13 was used for 'fertility'. Williams (1978) determined that this is the average number of eggs produced by each female but it is important to notice that the same author also refers a $24.1-31.7 \%$ brood mortality. Nevertheless, in our case the calibration of the model indicated that this value would produce better results. No data are available from the study population due to egg loss during handling. This model version, like version (d), also relies on Eqs. (8)-(11) in order to simulate recruitment. Table 2 provides the values used for each parameter, initial values of each state variable and also an explanation for the meaning of each model component.

\section{Results}

Stella (version 5.1.1) with Euler integration method and a time step of 1 day were used in order to run the model. The choice of the time step was based on the need to be able to operate the switches that would start the reproduction. Larger time steps jump over the dates for the onset of reproduction. Time steps of 0.1 days had no impact (zero sensitivity) on any of the simulations at a short or longer term (1-5 years) and were computationally heavy.

The simulation results for all model versions are presented in Fig. 1. Table 3 and Fig. 2 present the results of the comparison between observed and simulated values. Versions (a), (c) and (d) show poor results and should not be considered replicatively validated (sensu Power, 1993). They either present intercepts significantly different from zero (version (a)) (Cohen \& Cyert, 1961), slopes significantly different from one (version (c)) (Cohen \& Cyert, 1961) or even modelling efficiencies (EF) (Mayer \& Butler, 1993) below zero (version (d)).

Table 2

Components of the model version (e) and their values when applicable

\begin{tabular}{|c|c|c|c|c|}
\hline Type & Name & Value & Units & Description \\
\hline Forcing function & Temperature & Time series & ${ }^{\circ} \mathrm{C}$ & Air temperature at a nearby meteorological station \\
\hline Forcing function & Daylength & Time series & $\mathrm{h}$ & Duration of the daylight period \\
\hline Forcing function & Timenew & $1-365$ & Dimensionless & Julian day $(1-364)$ \\
\hline Parameter & Mortality_rate & 0.178 & per 28 days & Proportion dead at each age class ( 28 days) \\
\hline Parameter & Pctg_age 4 & 0.9 & Proportion & This is the proportion of immatures in age class 4 \\
\hline Parameter & Fertility & 13 & Recruits per female & An average number of individuals per female was used \\
\hline Parameter & Max_recruit_temp & 27 & ${ }^{\circ} \mathrm{C}$ & Recruitment does not occur above a certain temperature \\
\hline Parameter & Min_recruit_dayl & 13 & $\mathrm{~h}$ & Recruitment does not occur below a certain day length \\
\hline Parameter & Min_recruit_temp & 14 & ${ }^{\circ} \mathrm{C}$ & Recruitment does not occur below a certain temperature \\
\hline Parameter & Recruit_pulse_period & 14 & days & Number of days between each recruitment wave (semi-lunar) \\
\hline Parameter & Sex_ratio & 0.455 & females per total & Proportion of mature females in the adult population \\
\hline State variable & Age 1 & $0^{\mathrm{a}}$ & ind $\mathrm{m}^{-1}$ shoreline & Individuals of the age class per meter of shoreline \\
\hline State variable & Age 2 & $0^{\mathrm{a}}$ & ind $\mathrm{m}^{-1}$ shoreline & Individuals of the age class per meter of shoreline \\
\hline State variable & Age 3 & $0^{\mathrm{a}}$ & ind $\mathrm{m}^{-1}$ shoreline & Individuals of the age class per meter of shoreline \\
\hline State variable & Age 4 & $0^{\mathrm{a}}$ & ind $\mathrm{m}^{-1}$ shoreline & Individuals of the age class per meter of shoreline \\
\hline State variable & Age 5 & $253^{\mathrm{a}}$ & ind $\mathrm{m}^{-1}$ shoreline & Individuals of the age class per meter of shoreline \\
\hline State variable & Age 6 & $0^{\mathrm{a}}$ & ind $\mathrm{m}^{-1}$ shoreline & Individuals of the age class per meter of shoreline \\
\hline State variable & Age 7 & $193^{\mathrm{a}}$ & ind $\mathrm{m}^{-1}$ shoreline & Individuals of the age class per meter of shoreline \\
\hline State variable & Age 8 & $235^{\mathrm{a}}$ & ind $\mathrm{m}^{-1}$ shoreline & Individuals of the age class per meter of shoreline \\
\hline State variable & Age 9 & $153^{\mathrm{a}}$ & ind $\mathrm{m}^{-1}$ shoreline & Individuals of the age class per meter of shoreline \\
\hline State variable & Age 10 & $0^{\mathrm{a}}$ & ind $\mathrm{m}^{-1}$ shoreline & Individuals of the age class per meter of shoreline \\
\hline State variable & Age 11 & $0^{\mathrm{a}}$ & ind $\mathrm{m}^{-1}$ shoreline & Individuals of the age class per meter of shoreline \\
\hline Equation & Recruitment & Variable & ind $\mathrm{m}^{-1}$ shore day ${ }^{-1}$ & Equation for daily recruitment (see Table 1) \\
\hline Equation & Recruitment_pulse & Variable & dimensionless & An internal switch taking a value of 0 or 1 (see Table 1$)$ \\
\hline Equation & Juveniles & Variable & ind $\mathrm{m}^{-1}$ shoreline & Number of non-mature individuals (see Table 1) \\
\hline Equation & Adult_females & Variable & ind $\mathrm{m}^{-1}$ shoreline & Number of reproductive females (see Table 1) \\
\hline Equation & IST $^{-}$ & Variable & ind $\mathrm{m}^{-1}$ shoreline & Sum of all the individuals in all the age classes \\
\hline
\end{tabular}

\footnotetext{
${ }^{\text {a }}$ Initial values are presented.
} 

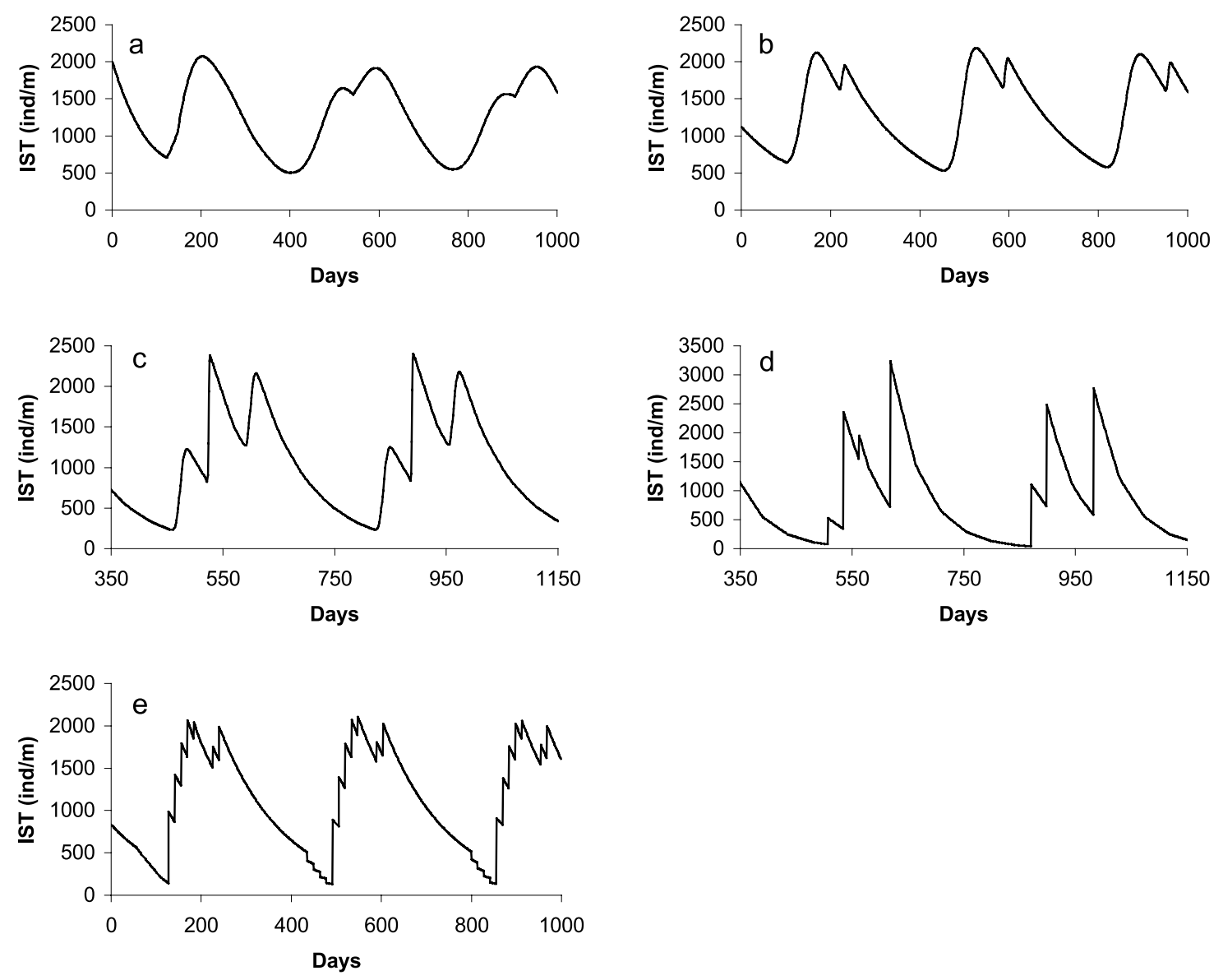

Fig. 1. Simulations performed using different mechanisms to simulate recruitment. (a) A single and long reproduction period only dependent on the day of the year was used. (b) Two reproduction periods dependent on the day of the year. (c) Three reproduction periods dependent on the day of the year. (d) Reproduction on a lunar basis, dependent on the temperature and day length. (e) Reproduction on a semi-lunar basis, dependent on the temperature and day length, but with age classes with a different length. Panels ' $c$ ' and 'd' present simulation results after an initiation run of ca. 1 year. IST, individuals per strip transect expressed as individual per meter of shoreline.

Replicative validity only applies to versions (b) and (e). Version (e) presents the closest slope to one and the closest intercept to zero, despite the higher $r^{2}$ and modelling efficiency presented by version (b).

In versions (a) and (b) the observed abundances (Fig. 2) are smoothed data, calculated as an average of three points in order to eliminate abnormal (IST, ind $\mathrm{m}^{-1}$ ) oscillations in consecutive sampling dates. Version (a) corresponds to a simulation of a single and long

Table 3

Statistical estimates for the simulated vs. observed plots regarding all the model versions

\begin{tabular}{|c|c|c|c|c|c|c|c|c|}
\hline \multirow[b]{2}{*}{ Version } & \multirow[b]{2}{*}{$r^{2}$} & \multicolumn{3}{|c|}{ Test for intercept $=0$} & \multicolumn{3}{|c|}{ Test for slope $=1$} & \multirow[b]{2}{*}{$\mathrm{EF}$} \\
\hline & & Intercept $t$ & & $p$ level & Slope & & $p$ level & \\
\hline $\mathrm{a}$ & 0.625 & 501.912 & 2.664 & $+<0.05$ & 0.699 & -2.217 & $>0.05$ & 0.556 \\
\hline b & 0.653 & 262.605 & 1.091 & $>0.2$ & 0.950 & -0.287 & $>0.5$ & 0.307 \\
\hline $\mathrm{c}$ & 0.675 & 332.912 & 1.837 & $>0.05$ & 0.713 & -2.320 & $<0.05$ & 0.669 \\
\hline d & 0.108 & 436.045 & 0.983 & $>0.2$ & 0.421 & -1.915 & $>0.05$ & -1.043 \\
\hline $\mathrm{e}$ & 0.567 & -69.363 & -0.232 & $>0.5$ & 0.991 & -0.041 & $>0.5$ & 0.223 \\
\hline
\end{tabular}

$\mathrm{EF}$, modelling efficiency. recruitment period, and we can see that two bumps in the abundance (IST, ind $\mathrm{m}^{-1}$ ) line appear spontaneously (Fig. 1a). Version (b) corresponds to the simulation of two distinct recruitment waves and therefore simulated and observed values present a more similar behaviour (Fig. 2b). Model versions (c) and (d) in Fig. 2 represent a plot of simulated abundance (IST, ind $\mathrm{m}^{-1}$ ) data vs. non-smoothed field data. This last type of data presents bigger oscillations and is more in accordance with the type of simulations produced by this model version. Version (c) uses three different periods of reproduction and although visually it seems to present good results (Fig. 2c) this is not corroborated by statistical analysis (Table 3). Version (d) gave weak long-term stability and therefore only the data from two consecutive years are presented (Fig. 1d). Version (e) shows the best fit between the smoothed observed data and simulated abundances of Talitrus saltator (Fig. 2e and Table 3). It uses temperature and day length dependencies for a recruitment occurring on a semi-lunar periodicity.

Sensitivity analysis was performed after the verification phase and before the calibration of the final model 

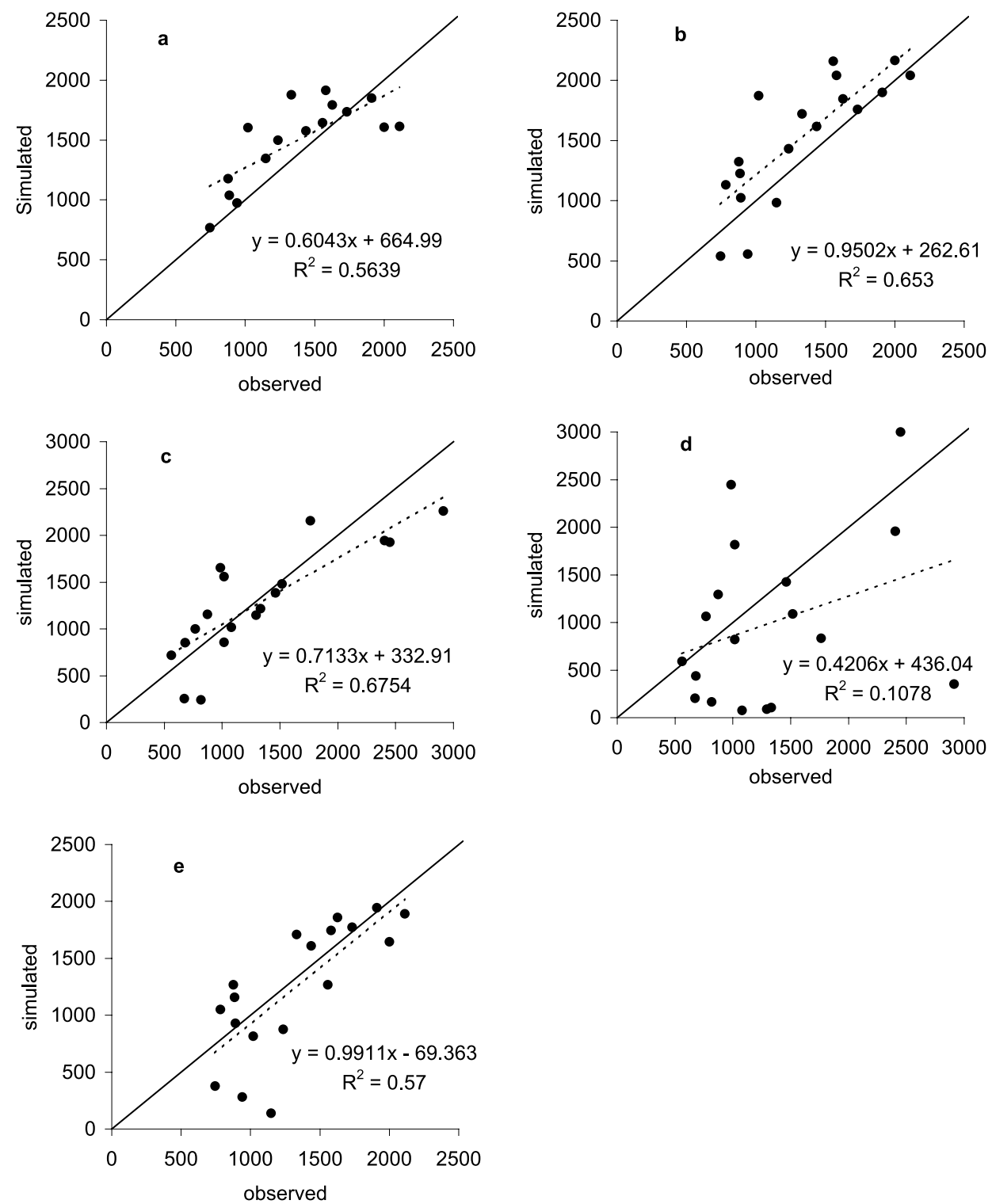

Fig. 2. Simulated vs. observed values for each model version. The dark line represents an ideal situation with a $100 \%$ match of simulated vs. observed values. The broken line is the regression line for the values obtained.

version (version (e)), by the procedure described by Jørgensen (1988) and Haefner (1996). The state variable chosen for the sensitivity analysis was the number of individuals per strip transect (IST, ind $\mathrm{m}^{-1}$ ) because it is also the state variable being used for calibration and replicative validation purposes. The effects caused on the abundance (IST, ind $\mathrm{m}^{-1}$ ) by \pm 10 and $\pm 50 \%$ changes in the parameters and initial values were tested (Table 4). As several initial values were zero it was therefore impossible to use the formula to test for the sensitivity of those initial values.

The abundance (IST, ind $\mathrm{m}^{-1}$ ) of Talitrus saltator is deeply affected by variations in the minimum recruitment day length (min_recruit_dayl), the minimum temperature for recruitment (min_recruit_temp), and
Table 4

Sensitivities of the individuals per strip transect (IST, ind $\mathrm{m}^{-1}$ ) of Talitrus saltator to several model parameters

\begin{tabular}{lrrrr}
\hline & \multicolumn{3}{l}{ Sensitivities of IST } & \\
\cline { 2 - 5 } & $+50 \%$ & $+10 \%$ & \multicolumn{1}{c}{$-10 \%$} & \multicolumn{1}{c}{$-50 \%$} \\
\hline Mortality rate & -1.041 & -1.460 & -1.764 & -2.678 \\
Pctg age 4 & -0.228 & -1.028 & -1.028 & -1.028 \\
Fertility & 0.810 & 0.765 & 0.742 & 0.696 \\
Max recruit temp & 0.000 & 0.000 & 0.847 & 1.278 \\
Min recruit dayl & -1.278 & -3.038 & -45.036 & -44.113 \\
Min recruit temp & -1.031 & -2.748 & -11.261 & -2.252 \\
Recruit pulse period & -0.397 & 13.962 & -12.159 & -2.868 \\
Sex ratio & 0.810 & 0.765 & 0.742 & 0.696 \\
Age 5 & 0.708 & 0.708 & 0.708 & 0.708 \\
Age $7^{\text {a }}$ & 0.172 & 0.172 & 0.172 & 0.172 \\
Age $8^{\text {a }}$ & 0.082 & 0.082 & 0.082 & 0.082 \\
Age $9^{\text {a }}$ & 0.036 & 0.036 & 0.036 & 0.036 \\
\hline
\end{tabular}

${ }^{\mathrm{a}}$ Initial values. 
the period between each recruitment wave (recruit_pulse_period). These parameters have a strong influence on the timing of reproduction and on abundance (IST, ind $\mathrm{m}^{-1}$ ) as opposed to the maximum temperature for recruitment (max_recruit_temp), which seems rather unimportant for model performance. Also important is the sensitivity to 'mortality rate', showing an inverse reaction to changes in the parameter.

The results of the sensitivity analysis of population densities to each initial value of the state variables were equal for all the levels of change (i.e. 10 or $50 \%$ ). The abundance (IST, ind $\mathrm{m}^{-1}$ ) of Talitrus saltator was most sensitive to the initial number of individuals in age class 5 and least sensitive to the initial number in age class 9 .

\section{Discussion}

Five model versions (a)-(e) were built before finding the adequate structure. Versions (a), (c) and (d) should not be considered validated, and were unable to replicate the abundances of Talitrus saltator observed in the study site. Only the model versions (b) and (e) passed all the statistical tests. Model versions (a)-(c), regardless of their statistical validity, were insufficient for the model purposes but provided clues on which direction to move. In these versions recruitment was simply started by the day of the year. This has no direct biological meaning in terms of regulation of the onset of recruitment although photoperiod depends on the day of the year. Version (d) used day length and temperature in order to start the recruitment. Nevertheless this model version had a poor long-term stability. In versions (a)(d) efforts to improve the modelling efficiency resulted in unrealistically high mortality rates. This is what led to the implementation of model version (e), which is in fact simpler but it is an explanatory model including causality. Version (e) also showed the best results regarding the statistical analysis performed. Therefore this approach is the model being discussed in the following paragraphs.

The relative importance of precise knowledge about each process and parameter was demonstrated. There is high model sensitivity to changes in the structure and parameters of the recruitment mechanism. This is serious when several model versions were sequentially tested using different recruitments. As expected the value of the mortality rate is important for the stability of the model. A rate of 0.178 per 28 days was determined by calibration and it is equivalent to 0.00726 per day, which is close to both the average (0.00993) and the median (0.00638) values for the field data cohorts.

The process of model construction highlighted the need for further studies on the factors influencing the timing of reproduction and recruitment. A laboratory study performed in the UK (Williams, 1985) and fieldwork by the same author (Williams, 1978) indicated that reproduction would start at a photoperiod above 14:10 (L:D). This value was considered the threshold and the environmental temperature had no significant influence upon it. This is clearly not the case in our population in which recruitment starts at temperatures above $14{ }^{\circ} \mathrm{C}$ and a photoperiod of $13: 10$ (L:D). These facts, even though not proving causality, result from observation of the field data (Marques et al., 2003). Moreover an arrest in recruitment due to high temperatures had to be included in the model in order to replicate the dynamics of the population. Even if it was considered that: (1) photoperiod is the key factor for reproduction as shown by Williams (1985) for a distant population; and (2) temperature only regulates the speed of the release of the young, the logical consequence of this would be that a photoperiod below $13: 10$ (L:D) would initiate reproduction. The reason for this is that recruitment only occurs some time after the threshold value is reached.

It is not necessarily true that a species uses exactly the same mechanisms or the same threshold values for the beginning of the reproduction throughout the entire range of its distribution. Populations under different conditions may adapt their physiology in order to meet environmental conditions (Kevin \& Spicer, 1998; Morrit \& Spicer, 1998). This is possibly the case of Talitrus saltator in which different populations present different recruitment timing processes.

So far the model attained the calibration phase and its replicative validity is demonstrated. The question to be posed is if it will make correct predictions under different situations. This could mean another year in the same or a nearby location or a totally different and remote Talitrus saltator population. If one of the above is achieved then the model can be considered validated i.e. tested with an independent data set (Jørgensen, 1988). Under the MECO project a considerable amount of data has been produced regarding $T$. saltator population dynamics in two Mediterranean countries (Italy and Tunisia). This will hopefully provide an opportunity to test the predictive validity (Power, 1993; Rykiel, 1996) of the model and therefore increase its robustness. This tool when used alone or coupled with other models, may be useful in assessing the effects of human actions upon the sandy beach ecosystem.

\section{Acknowledgements}

This work was carried out in the scope of the research project 'Bases for the integrated sustainable management of Mediterranean sensitive coastal ecosystems', funded by the European Union (IC18-CT98-0270) and by the project POCTI/CTA/36553/00 funded by FCT. The authors are indebted to Dr Isabella Colombini for 
supplying a summary of data regarding Talitrus saltator bioecology. This was a strong push forward for the beginning of the construction of the model.

\section{References}

Anastácio, P. M., Nielsen, S. N., \& Marques, J. C. (1999). CRISPcrayfish rice integrated system of production. 2. Modelling crayfish (Procambarus clarkii) population dynamics. Ecological Modelling $123,5-16$.

Bertalanffy, L. V. (1957). Quantitative laws in metabolism and growth. The Quarterly Review of Biology 32, 217-231.

Bowie, G. L., Mills, W. B., Porcella, D. B., Campbell, C. L., Pagenkopf, J. R., Rupp, G. L., Johnson, K. M., Chan, P. W. H., Gherini, S. A., \& Chamberlain, C. E. (1985). Rates, constants and kinetics formulations in surface water modelling (p. 299). Athens, USA: United States Environmental Protection Agency, Environmental Research Laboratory, EPA/600/3-85/040.

Brazeiro, A., \& Defeo, O. (1996). Macroinfauna zonation in microtidal sandy beaches: is it possible to identify patterns in such variable environments? Estuarine, Coastal and Shelf Science 42, 523-536.

Bregazzi, P. K., \& Naylor, E. (1972). The locomotor activity of Talitrus saltator (Montagu) (Crustacea: Amphipoda). Journal of Experimental Biology 57, 375-391.

Brown, A. C., \& McLachlan, A. (1990). Ecology of sandy shores. Amsterdam: Elsevier.

Cohen, K. J., \& Cyert, R. M. (1961). Computer models in dynamic economics. The Quarterly Journal of Economics 75, 112-127.

Dahl, E. (1945). The amphipoda of the Sound. Part I-Terrestrial amphipoda. Lunds Universitets Arsskrift. N. F. Avd 2 42, 1-53.

Dahl, E. (1952). Some aspects of the ecology and zonation of the fauna of sandy beaches. Oikos 4, 1-27.

David, R. (1936). Recherches sur la biologie et intersexualité de Talitrus saltator Mont. Buletin Biologique de la France et de la Belgique 70, 332-357.

Fallaci, M., Aloia, A., Audoglio, M., Colombini, I., Scapini, F., \& Chelazzi, L. (1999). Differences in behavioural strategies between two sympatric Talitrids (Amphipoda) inhabiting an exposed sandy beach of the French Atlantic Coast. Estuarine, Coastal and Shelf Science 48, 469-482.

Haefner, J. W. (1996). Modeling biological systems. Principles and applications (p. 183). New York: ITP-Chapman and Hall.

Jørgensen, S. E. (1988). Fundamentals of ecological modelling. Amsterdam: Elsevier.

Kevin, J. G., \& Spicer, J. I. (1998). Do upper thermal tolerances differ on geographically separated populations of the beachflea Orchestia gammarellus (Crustacea: Amphipoda)? Journal of Experimental Marine Biology and Ecology 229, 265-276.

Lagardere, J. P. (1966). Recherches sur la biologie e l'ecologie de la macrofaune des substrats meubles de la cote basque. Bulletin $d u$ Centre d'Etudes et de Recherches Scientifiques Biarritz 6, 143-209.

Marques, J. C., Gonçalves, S. C., Pardal, M. A., Chelazzi, L., Colombini, I., Fallaci, M., Bouslama, M. F., El Gtari, M., CharfiCheikhrouha, F. \& Scapini, F. (2003). Comparison of Talitrus saltator (Amphipoda, Talitridae) biology, dynamics, and secondary production in Atlantic (Portugal) and Mediterranean (Italy and Tunisia) Populations. Estuarine, Coastal and Shelf Science, 58.
Mayer, D. G., \& Butler, D. G. (1993). Statistical validation. Ecological Modelling 68, 21-32.

McLachlan, A., Erasmus, T., Dye, A. H., Wooldridge, T., van der Horst, G., Rossouw, G., Lasiak, T. A., \& McGwynne, L. (1981). Sandy beach energetics: an approach towards a high energy interface. Estuarine, Coastal and Shelf Science 13, 11-25.

Morritt, D. (1998). Hygrokinetic responses of talitrid amphipods. Journal of Crustacean Biology 18, 25-35.

Morritt, D., \& Spicer, J. I. (1998). The physiological ecology of talitrid amphipods: an update. Canadian Journal of Zoology 76, 1965 1982.

Nardi, M., Persson, L. E., \& Scapini, F. (2000). Diel variation of visual response in Talitrus saltator and Talorchestia deshayesii (Crustacea: Amphipoda) from high latitude beaches of low tidal amplitude. Estuarine, Coastal and Shelf Science 50, 333-340.

Palluault, M. (1954). Notes écologiques sur le Talitrus saltator L. Archives de Zoologie Experimentale et Générale 91, 105-129.

Power, M. (1993). The predictive validation of ecological and environmental models. Ecological Modelling 68, 33-50.

Rykiel, E. J., Jr. (1996). Testing ecological models: the meaning of validation. Ecological Modelling 90, 229-244.

Scapini, F. (1997). Variations in scototaxis and orientation adaptation of Talitrus saltator populations subjected to different ecological constraints. Estuarine, Coastal and Shelf Science 44, 139-146.

Scapini, F., Chelazzi, L., Colombini, I., \& Fallaci, M. (1992). Surface activity, zonation and migrations of Talitrus saltator on a Mediterranean beach. Marine Biology 112, 573-581.

Sokal, R. R., \& Rohlf, F. J. (1987). Introduction to biostatistics (p. 78). New York: Freeman.

Weslawski, J. M., Kupidura, T., \& Zabicki, M. (2000). Sandhoppers, Talitrus saltator (Montagu, 1808) (Amphipoda, Gammaridea), at the Polish Baltic Coast: seasonal and spatial distribution patterns. Crustaceana 73, 961-969.

Weslawski, J. M., Stanek, A., Siewert, A., \& Beer, N. (2000). The sandhopper (Talitrus saltator, Montagu 1808) on the Polish Baltic Coast. Is it a victim of increased tourism? Oceanological Studies 29, $77-87$.

Williams, J. A. (1978). The annual pattern of reproduction of Talitrus saltator (Crustacea: Amphipoda: Talitridae). Journal of Zoology, London 184, 231-244.

Williams, J. A. (1979). A semi lunar rythm of locomotor activity and moult synchrony in the sand beach amphipod Talitrus saltator. In E. Naylor \& G. Hartnoll (Eds.), Cyclic phenomena in marine plants and animals (pp. 407-414). New York: Pergamon Press.

Williams, J. A. (1983). Environmental regulation of the burrow depth distribution of the sand-beach amphipod Talitrus saltator. Estuarine, Coastal and Shelf Science 16, 291-298.

Williams, J. A. (1985). The role of photoperiod in the initiation of breeding and brood development in the amphipod Talitrus saltator. Journal of Experimental Marine Biology and Ecology 86, $59-62$.

Williams, J. A. (1995). Burrow zone distribution of the supralittoral amphipod Talitrus saltator on Derbyhaven beach, Isle of Man-a possible mechanism for regulating desiccation stress. Journal of Crustacean Biology 15, 466-475.

Williamson, D. I. (1951). On the mating and breeding of some semiterrestrial amphipods. Reports from the Dove Marine Laboratory $12,49-62$. 